\title{
THE POSITION OF THE OTTOMAN EMPIRE ON THE ISSUE OF THE MORISCOS AND ITS STRATEGY TOWARDS IT
}

\author{
Metin ŞERIFOĞLU ${ }^{1}$
}

\section{Istanbul / Türkiye \\ p. 488-502}

Received: 03/12/2021

Accepted: $17 / 12 / 2021$

Published: 01/01/2022

This article has been scanned I iThenticat No plagiarism detected

\begin{abstract}
:
This research deals with the issue of the Moriscan refugee crisis after the fall of Andalusia to the Spanish in 1492, and the brutal policies they carried out against the refugees. The research also deals with the policy of the Ottoman Empire towards this ordeal, which represented the largest global humanitarian crisis during the 16th and 17th centuries AD. The Ottoman Empire played a major role in the process of saving these Muslim and Jewish refugees, and their homeland in different parts of the Ottoman geography. The Ottoman Empire also succeeded in adopting an integrative policy for these refugees that took into account their social and sectarian specificities, as well as the societal privacy of the new settlement areas.

This policy has contributed to creating dynamism and vitality in these areas, and transforming Andalusian refugees into an active force on all cultural, social and economic levels. On the other hand, the Spanish and European refugee crisis revealed the mentality of the issue of religious freedom and the lack of recognition of other religious sects. At the same time, this crisis reflected the Ottoman mentality towards the issue of non-Muslim minorities and how the state interacted with them, and its ability to manage diversity within the Ottoman society.

In this context, we will try in this research to present a different analytical approach to the issue of Andalusian Muslim and Jewish refugees, as well as knowing the strategy of the Ottoman Empire towards it and the backgrounds that motivate it. This topic will be addressed through four axes as follows:

-First: Andalusia and its importance in attracting immigrants in the Middle Ages

-Second: The historical and political circumstances in which the Andalusian refugee crisis arose

-Third: The Andalusian refugee crisis and the position of the Ottoman Empire on it

-Fourth: The Ottoman Empire's strategy towards the refugee crisis -Fifth: The policy of the Ottomans towards the refugees from Andalusia.
\end{abstract}

Key words: Andalusia, Moriscos, Spaniards, Ottomans, Refugees, Jews.

http://dx.doi.org/10.47832/2717-8293.15.35

1 iD Dr. , Mardin Artuklu University, Türkiye, zoubeirk@ gmail.com 


\section{موقف الدولة العثمانية من أزمة المهاجرين الأندلسيين واستراتيجيتها تجاهها}

\section{متين شريف أوغلو 2}

الملخص: يتناول هذا البحث مسألة أزمة اللاجئين الموريسكين بعد سقوط الأندلس في يد الإسبان سنة 1492، وماقاموا به من سياسات وحشية ضد هؤلاء اللاجئين. كما يتطرق البحث إلى سياسة الدولة العثمانية بتحاه هذه المحنة التي مثلت أكبر الإسبان

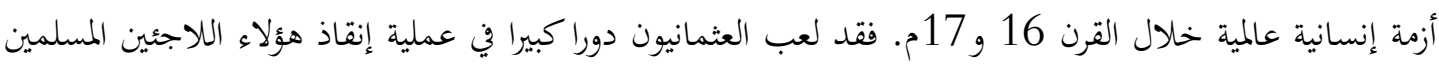
واليهود، ووطنتهم في أماكن متفرقة من الجغرافية العثمانية، كما نجحت الدولة العثمانية في انتهاج سياسة إدماجية لهؤلاء اللاجئين، راعت فيها الخصوصيات الاجتماعية والمذهبية لهم، وكذلك الخصوصية المجتمعية لمناطق التوطين الجلديدة. وقد ساهمت هذه السياسة في خلق ديناميكية وحيوية في هذه المناطق، وتحويل اللاجئين الأندلسيين إلى قوة فاعلة على ونى كافة المستويات الثقافية والاجتماعية والاقتصادية. من جهة أخرى كشفت أزمة اللاجئين الذهنية الإسبانية والأوروبية

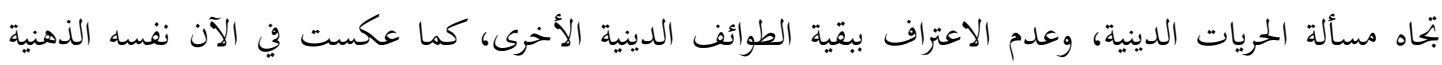
العثمانية بتحاه مسألة الأقليات غير الإسلامية، وكيف تفاعلت الدولة العثمانية معها، وقدرتها على إدارة التنوع داخل

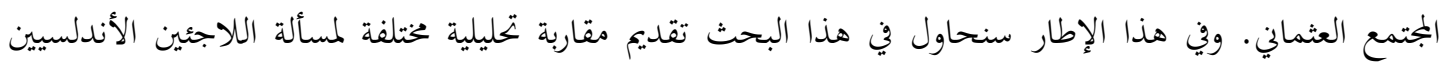
المسلمين واليهود، ووكذلك معرفة استرابتية الدولة العثمانية تجاهها، والخلفيات التي كانت تحركها. وسيتم تناول هذا الموضوع من خلال المحاور الخمسة التالية:

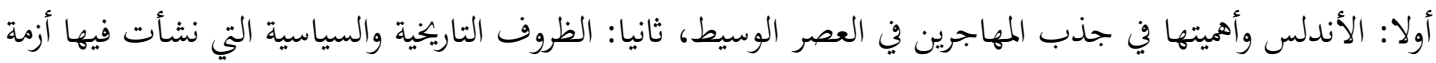
لاجئي الأندلس، ثالثا: أزمة اللاجئين الأندلسيين وموقف الدولة العثمانين فئنس منها، رابعا: استراتيجية الدولة العثمانية بتحاه

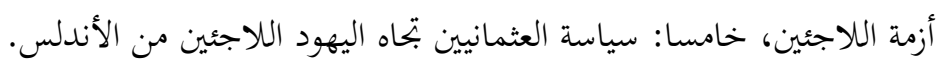
الكلمات المفتاحية: الأندلس، الموريسكيون، الإسبان، العثمانيون، اللاجئون، اليهود.

عندما نتأمل في التاريخ البشري نجد أن ظاهرة الهجرة واللجوء ظاهرة قديمة، وجدت منذ أن ظهر الإنسان على وجه هذه البسيطة. وقد عرفت مختلف مناطق العالم عدة موجات من الهجرة، ارتبطت أساسا بأسباب وعوامل مختلفة، منها ماهو إنساني، وماهو اقتصادي واجتماعي وثقافي وعسكري وغيرها. وقد كانت المنطقة العربية والإسلامية أحد أهم المناطق الرئيسية التي شهدت التهات

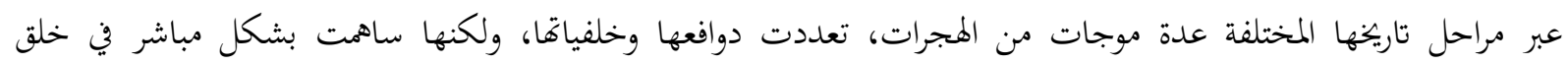

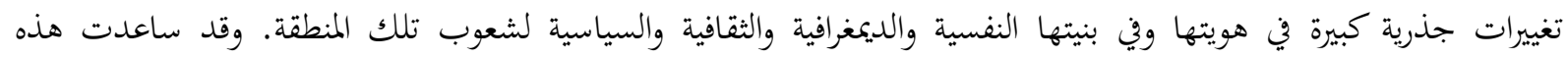
الهجرات على خلق حالة من التنوع الثقافي والعرقي والديني، ساهم في ظهور تبارب سياسية وثقافية وحضارية، تفاعلت فيها الثقافة

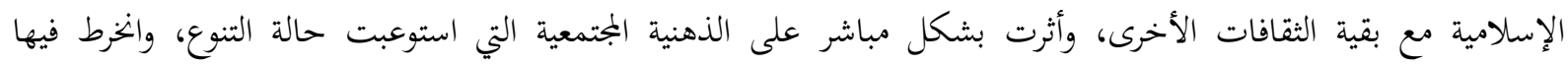
المهاجرون الجلدد بشكل تلقائي، وتحولوا إلى عنصر فاعل في تشكيل المنظومة الاجتماعية والسياسة والثقافية لتلك المناطق. وقد بلغ تأثير هذه الهجرات على منطقة العالم الإسلامي إلى درجة ظهور دول جديدة، أسس فيها اللاجئون القادمون من

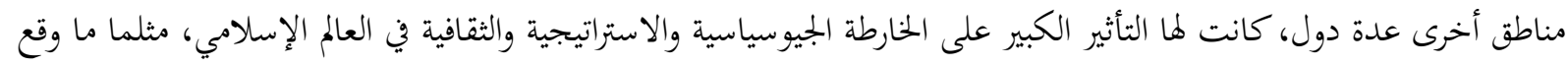


في منطقة الأناضول التي شهدت بداية من القرن العاشر ميلادي هجرات واسعة للقبائل التركمانية، قدموا من آسيا الوسطى، خصوصا بعد معركة ملاذكرد سنة 1071م. حيث نجحت الدولة السلجوقية بقيادة ألب أرسلان في تغيير المعادلة السياسية والاستراتجية والثقافية في منطقة الاناضول، ونجح في السيطرة عليها عبر استراتجية تشجيع القبائل التركمانية على الهجرة إلى منطقة الأناضول، وقدَّم لهم كل التسهيلات الضرورية لتحقيق عوامل الاستقرار فيها، والانخراط في نسيجها المجتمعي الذي تغير بفضل قوة تدفق اللاجئين التركمانية إلى مجتمعات تركية إسلامية.

وقد ساهت هذه الهجرات بشكل رئيسي في تدعيم أسس دولة سلاجقة الروم في منطقة الأناضول، وكذلك في ظهور أهم دولة في التاريخ السياسي الإسلامي بعد اهيار دولة السلاجقة، تمثلت في الدولة العثمانية التي كانت تنتمي إلى قبيلة قايي إحدى القبائل التركمانية القادمة إلى منطقة الأناضول في العهد السلجوقي، وقد تمكنت هذه القبيلة بقيادة عثمان غازي من تأسيس دولة

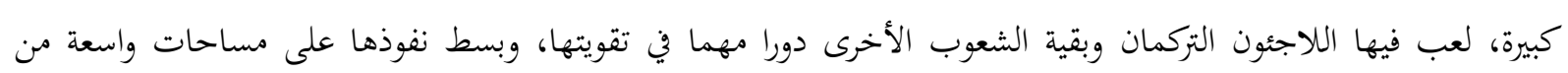
خريطة العالم الإسلامي وقسم واسع من القارة الأوروبية، كما أصبحت هذه الدولة لاعبا أساسيا في السياسة الدولية، خصوصا بعد فتح السلطان محمد الفاتح للقسطنطينية سنة 1453م، وتحويلها إلى عاصمة للإمبراطورية العثمانية التي بدأت تتوسع مساحتها الجغرافية، وانضوت تحت حكمها عدة شعوب وعرقيات ومذاهب أخرى، وأصبحت مركز جذب للهجرات الوافدة. غير أنه وفي الوقت الذي كانت فيه منطقة الشرق الإسلامي تشهد ظهور دولة إسلامية قوية، تؤمن بحالة التنوع الثقافي والديني والعرقي، وتشجع على الهجرات إليها لتسفيد من خبراتا المختلفة، كانت منطقة المغرب الإسلامي، وتحديدا في بلاد الأندلس تشهد في الآن نفسه حالة من الاهيار الشامل والسقوط في يد الإسبان الذين مارسوا تطهيرا عرقيا ودينيا بشعا جدا، لمج يشهد له العالم مثيلا. مما دفع بالمسلمين واليهود إلى الهروب من الأندلس وتركها، واللجوء إلى عدة أماكن مختلفة في أوروبا وفي شمال إفريقيا. وقد عكست هذه الممارسات التطهيرية حالة الذهنية الانتقامية المتطرفة التي لم تكن تؤمن بأي تنوع ثقافي أو ديني أو عرقي، بل إن هذه الذهنية الإسبانية لم تكن تعترف حتى ببقية المذاهب المسيحية الأخرى، وانتهجت بعد سقوط الأندلس سنة 1492م سياسة تصفية لكل الأديان الأخرى كالمسلمين واليهود والأورثودكس وغيرها. وفي ظل هذا المناخ التطهيري المرعب في إنبه الأندلس تعالت أصوات المسلمين اللاجئين الذين استنجدوا بالسلطان العثماني بداية القرن 16 من أجل إنقاذ حياقم، وإنقاذ معتقداتم وعائلاتم وأطفالهم ومتنلكاتم.

وأمام تفاقم أزمة اللاجئين في منطقة البحر الأبيض المتوسط، وتدفق أعداد كبيرة منهم على المناطق العثمانية، وازدياد سياسة الاضطهاد الاسباني للمسلمين واليهود تحركت الدولة العثمانية نخو إنقاذ هؤلاء اللاجئين، وانتهجت سياسة واسترابجية فعالة، ساهمت في إنقاذ الآلاف من اللاجئين، وتوطينهم في مناطق مختلفة من جغرافيتها. وقد وضعت الدولة العثمانية استراتيجية إدماجية لهؤلاء اللاجئين لكي ينخرطوا في مناطق التوطين الجديدة، والاستفادة من قدراهم وإمكانياهم وخبراتم. وقد اكتست هذه الاستراتيجية فعالية كبيرة، واستوعبت كل اللاجئين، بغض النظر عن انتماءاتم الدينية أو المذهبية، وساعدتم على الانخراط في بنية المجتمع العثماني المتنوع، حيث استفاد هؤلاء من مناخ الحريات الدينية ومن القوانين والتشريعات التي كانت سائدة في الجغرافية العثمانية.

-

تكمن أهمية هذا البحث في تسليط الضوء على محنة اللاجئين الأندلسين وموقف الدولة منها واستراتيجيتها في إنقاذ هؤلاء اللاجئين. فرغم أن العديد من الدراسات التاريخية قد تناولت مثل هذه المواضيع إلا أها لم تركز بشكل أوسع على الدور العثماين 
في التعاطي مع مسألة اللاجئين الأندلسيين المسلمين واليهود على حد سواء، ولم تتطرق إلى واستراتيجية توطينهم وإدماجهم في أماكن مختلفة من الجغرافية العثمانية.

\section{- أهدف البحث:}

يرمي هذا البحث إلى تحقيق عدة أهداف أساسية أهمها: - معرفة الظروف التاريخية والسياسية التي نشأت فيها أزمة اللاجئين الأندلسيين، وخلفياتما الدينية والاقتصادية والاجتماعية. - معرفة التداعيات التي خلفتها أزمة اللاجئين الأندلسيين وانعكاساتها على خريطة التوازنات الإقليمية والدولية

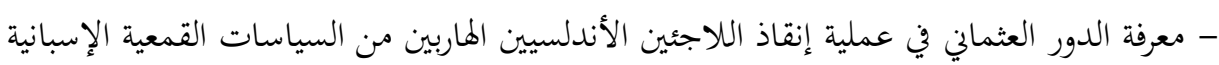

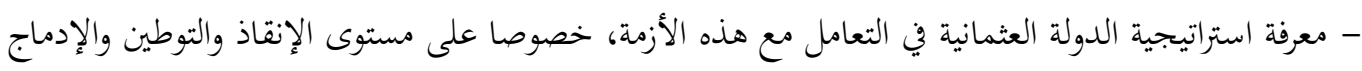
- معرفة موقف الدولة العثمانية واستراتيجيتها بتحاه اللاجئين اليهود الذين فروا من إسبانيا - معرفة وضعية الحريات الدينية في كل من الجغرافية العثمانية والدول الاوروبية خصوصا إسبانيا وفرنسا وإبجلترة

\section{- منهجية البحث:}

سيتم في هذا البحث تقديم قراءة تحليليلة تاريخية واستقرائية لمسألة اللاجئين الأندلسيين، وسيتم اتباع المنهجية التالية: - مقدمة - المحور الأول: الأندلس وأهميتها في جذب المهاجرين في العصر الوسيط

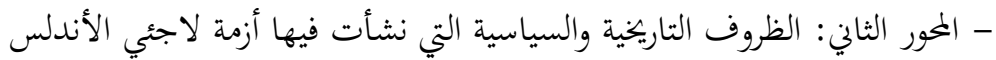
- المحور الثالث: أزمة اللاجئين الأندلسيين وموقف الدولة العثمانية منها لتهيه - المحور الرابع: استراتيجية الدولة العثمانية بحاه أزمة اللاجئين

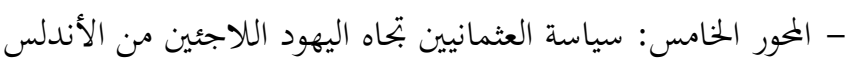
- الخاتمة -

\section{1- الأندلس وأهميتها في جذب المهاجرين خلال العصر الوسيط:}

لعله من المفيد حتى نفهم أزمة اللاجئين الأندلسيين بعد سقوط الأندلس أن نشير هنا إلى أن الأندلس كانت مركز جذب

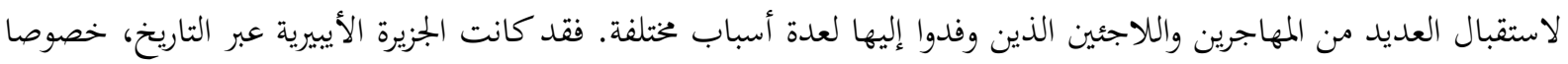
في فترة الحكم الإسلامي ملجأ آمنا للكثير من الشعوب اللاجئة، وذلك لطبيعة المناخ السياسي والاقتصادي والثقافي والحريات الدينية والفكرية التي توفرت في تلك المنطقة. ويمكن القول إن هناك أسباب مختلفة لتدفق اللاجئين على منطقة الأندلس خلال فئل فترة العصر الوسيط. ويأتي الدافع الديني في مقدمة هذه الأسباب، حيث اتسمت فترة الحكم الإسلامي في الأندلس بالحريات الدينية، الأمر الذي جعلها وجهة للعديد من الأقليات الدينية المضطهدة، خصوصا في أوروبا التي كانت تمارس سياسة الاضطهاد الديني، وكانت الكنيسة تمارس ضغطا كبيرا على مخالفيها من بقية الأقليات الدينية الأخرى، ومنها اليهود الذين تعرضوا إلى اضطهاد كبير،

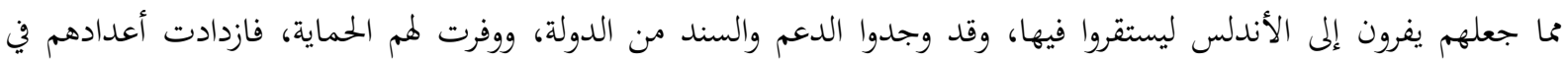

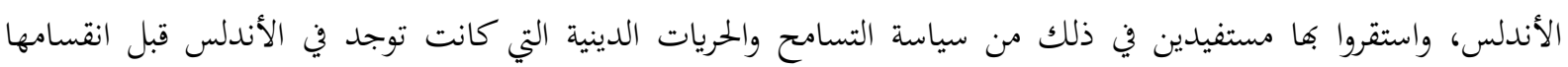
(حوراني، 2008، الصفحات 230-233). 
أما الدافع الثاني فهو دافع علمي، وذلك بسب ازدهار الحياة العلمية والفكرية التي شهدها الأندلس، ووجود العلماء

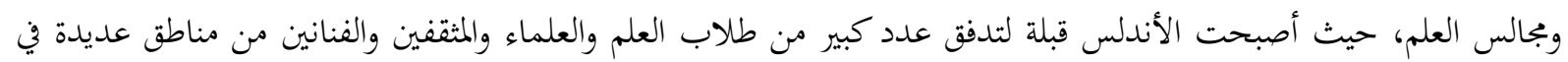

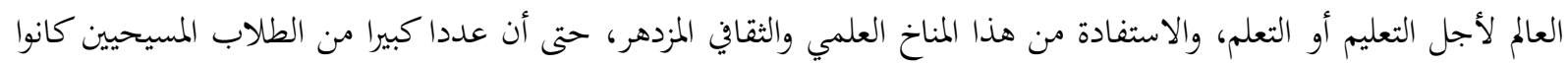

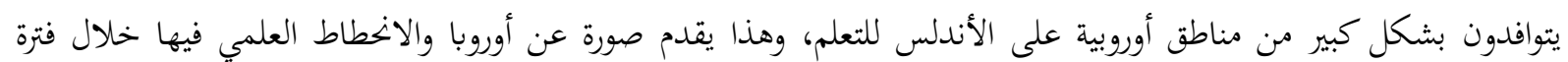

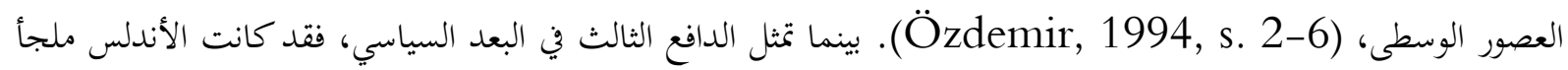
للكثير من المعارضين للدولة العباسية وللفاطميين ومن المعارضين للكنيسة. وقد استفاد كل هؤلاء من الحريات السياسية والدينية التي وجدت في فترة الحكم الإسلامي في الأندلس قبل فترة انقسامها، وقد تم استقبالهم من قبل الدولة، ووفرت لهم الحماية الكاملة من منطلق إنساني أخلاقي ديني، وكذلك من منطلق سياسي للاستفادة منهم في تعاملاقا مع تلك الدول التي فر منها هؤلاء جراء الاضطهاد السياسي الذي مورس عليهم، أو جراء التمرد والفتن التي عرفتها تلك المناطق (Lütfi, 2007, s. 30- (28). أما الدافع الرابع لتدفق الموجات على منطقة الجزيرة الآيبيرية فيتمثل في البعد الاقتصادي، حيث شهدت بلاد الأندلس في

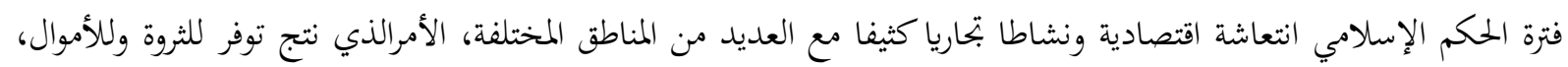

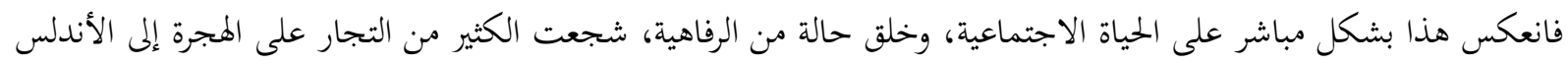

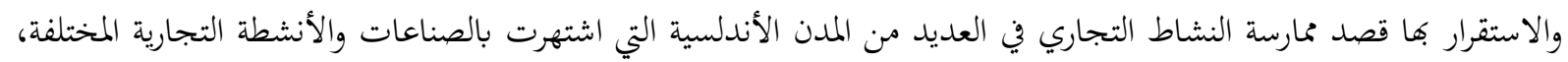

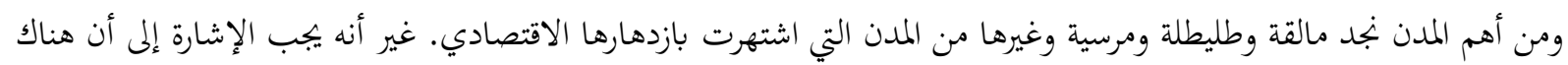

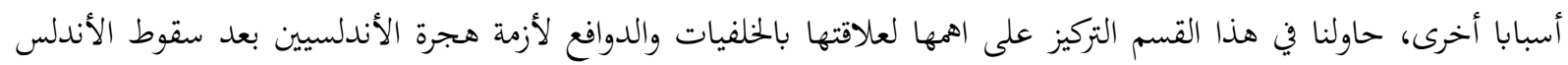

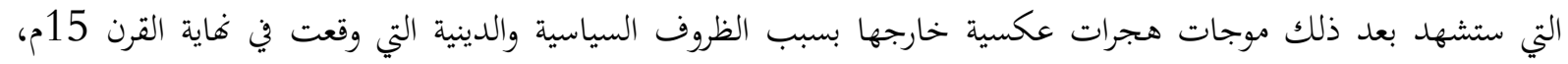

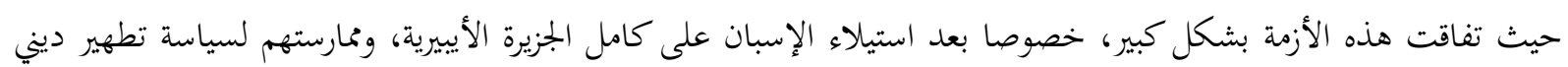
وحشية واسعة ضد المسلمين واليهود الذين كانوا يقطنون في الأندلس (4ka (Aka) 1997, s. 42).

\section{2- الظروف التاريخية والسياسية التي نشأت فيها أزمة مهاجري الأندلس:}

ظهرت أزمة اللاجئين في ظل ظروف تاريخية وسياسية صعبة شهدةا منطقة الأندلس نتيجة الانقسامات الطائفية وتراجع

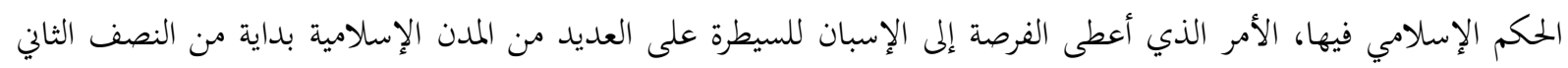
من القرن 15م. لذلك بدأ الخوف يدب في الكثير من سكان الأندلس، وشرع الكثير منهم يفكر في الهجرة ومغادرة الأندلس بحثنا عن أماكن أكثر أمانا واستقرارا. وقد أصبحت الأندلس محاصرة بعدة ممالك مسيحية، تترصد سقوطها للاستيلاء عليها، مثل مملكة البرتغال وقسطيلية والأراغون التي كانت تشن هجمات متكررة على المدن الإسلامية من أجل السيطرة عليها، وقد عانى السكان السان

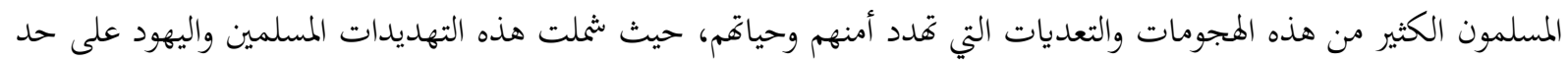
سواء، وبات واضحا أن الإسبان المسيحيين وبقية الممالك المسيحية الكاتوليكية متفقة فيما بينها على القيام بعمليات تطهير ديني وعرقي لكل المسلمين واليهود دون تمييز (Paşa, 2011, s. 23-24).

وقد آلت هذه الظروف السياسية الصعبة إلى سقوط مدينة غرناطة في يد الإسبان سنة 1492م، وبذلك ينتهي الوجود

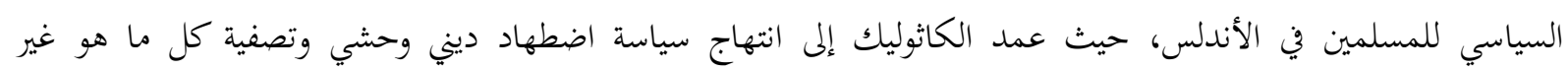
مسيحي، خصوصا من المسلمين واليهود، وتشكلت محاكم تفتيش لهذا الغرض، بتجبر المسلمين واليهود على ترك دياناتمب، وتجبرهم على اعتناق المسيحية والمذهب الكاثولوكي، كما تم سجن وقتل ونفي الكثير من رفضوا هذه الأوامر. وكانت الملكة وإليزابيت قد فئد أصدرت مع زوجها فرديناند مرسوما يمهل المسملين واليهود عشرة أشهر لترك منطقة الأندلس، ومن يخالف هذئ هذا القرار يعرض نفسيه 
إلى السجن أو القتل. وقد مثل هذا القرار إعلان الحرب من المسيحيين على كل ديانة أخرى تخالف المسيحية والمذهب الكاثوليكي، وقرارا بدأت بموجبه ممارسة عمليات تطهير ديني واسعة، استعملت فيها كل الوسائل الوحشية والبشعة والتنكيل

بالمسلمين واليهود الذين وجدوا أنفسهم مجبرين على ترك البلد خوفا على معتقداتم وأرواحهم (Güleryüz, 2015, s. 57). وفي ظل هذا المناخ السياسي الجديد الذي تيمن عليه ممارسات قمعية ووحشية بدأ الإسبان ومحاكم التفتيش في تطبيقها ضد المسلمين واليهود، فقد حدثت عدة ثورات وانتفاضات ضد السياسة الإسبانية، قابلتها السلطات الإسبانية بسياسة قمع وحشية، ومارست إبادات جماعية، وراح ضحيتها الآلاف من المسلمين المدافعين عن حرياتم الدينية، حيث عرفت هذه المرحلة موجات هجرة واسعة من المسلمين واليهود الفارين من القمع الإسباني، فقد لجأ هؤلاء إلى العديد من المناطق المختلفة، مثل شمئل منال

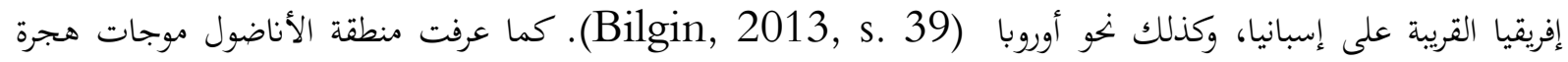
واسعة، وتدفق عدد كبير من اللاجئين الأندلسيين إلى مناطق الدولة العثمانية بحثا عن الأمان، الأمر الذي جعل السلطات

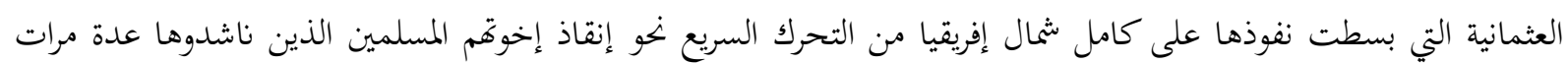

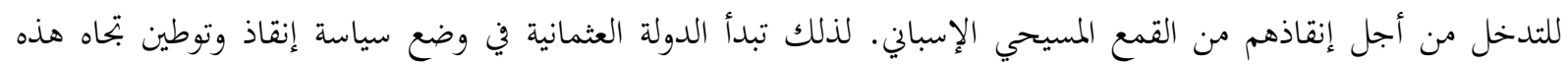
الموجات الكبيرة من اللاجئين المسلمين واليهود (Özdemir, 1994, s. 229). فكيف كانت سياسة الدولة العثمانية بتحاه أزمة اللازمة؟ وما هي الوسائل التي انتهجتها في التعامل معها؟ وماهي الحنفيات التي كانت تحرك الدولة العثمانية في استقبال مثل

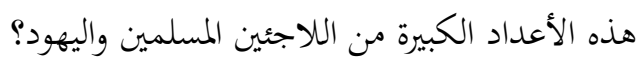

3- أزمة اللاجئين الأندلسيين وموقف الدولة العثمانية منها:

شكل المشروع الإسلامي العثماني في منطقة الشرق الإسلامي تمديدا كبيرا للدول المسيحية في أوروبا، خصوصا بعد فتح القسطنطينية، حيث انتهج العثمانيون بعد هذه المرحلة سياسة توسعية في ابتاه أوروبا، وبقدر ما كانت هذه الاستراتيجية مخيفة ومزعجة للغرب، فقد كانت في الوقت نفسه أملا وخلاصا جديدا بالنسبة إلى بقية شعوب الجغرافيا الإسلامية، خصوصا المسلمين في الأندلس، أملا وقوة دعم لهم على الأقل معنويا ضد التهديد المسيحي المحدق بكم في شثمال الجزيرة الأيبيرية، لذلك عمت الفيك الفرحة والسرور كل مناطق العالم الإسلامي عندما تواردت أخبار فتح القسطنطينية، وتويلها إلى عاصمة إسلامية، أصبحت قبلة جذئب

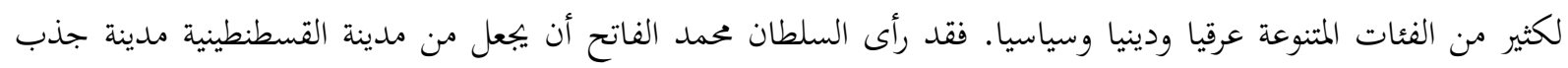

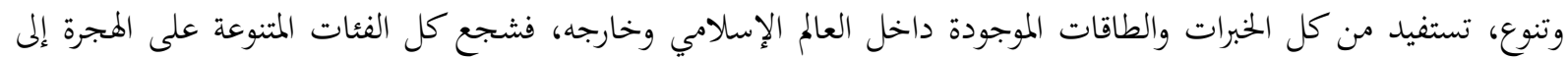
استانبول، وسهل لكثير من الأرمن واليهود وبقية الطوائف الأخرى عملية القدوم والدعم اللوجستي والمادي، ومنحهم حقوقهم الدينية وحرية معتقداتم وماية معابدهم وكنائسهم، بل إن السلطان محمد الفاتح أصدر نظام الملل لحماية حقوق الاقليات غير وني

المسلمة في الجغرافيا العثمانية، وكانت مؤسسة نظام تحت مراقبة السلطان نفسه (C.E.BOSWORTH, 1982, s. 37). خلال هذه المرحلة التاريخية بدأت العلاقات العثمانية الأندلسية تتوطد وتتعزز، خصوصا في عهد السلطان بايزيد الثاني الذي أرسل له آخر ملوك غرناطة عبد الله الصغير رسولا ليشرح له أوضاع المسلمين في الأندلس، ويعطيه فكرة شاملة حول بله

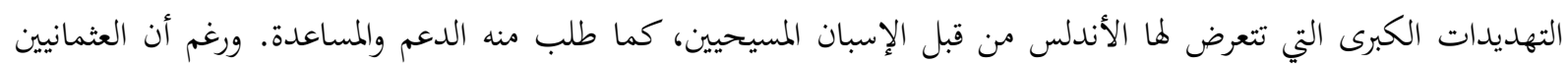

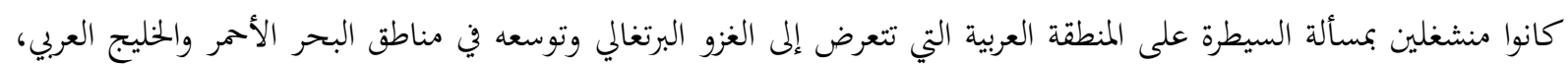

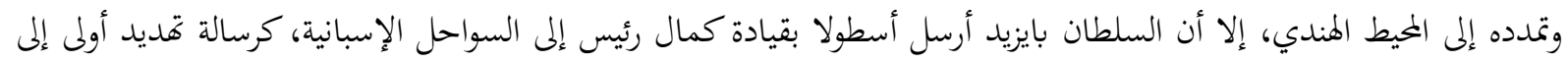
إسبانيا من أجل الضغط عليها للكف عن اضطهاد المسلمين في الأندلس من ناحية أولى، وكذلك من أجل نقل اللاجئين المسلمين واليهود الفارين إلى ثمال إفريقيا إلى العديد من المناطق المختلفة من ناحية ثانية (122-Sakaoğlu, 2002, s. 119). 
ويمكن القول إن العلاقات بين العثمانيين والأندلسيين بدأت تأخذ منعطفا أكبر مع صعود السلطان سليمان القانوني إلى

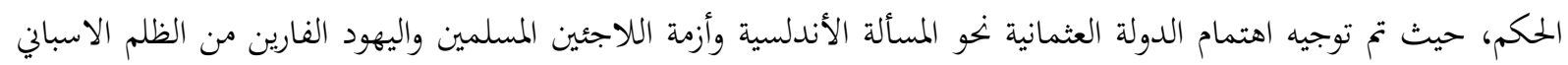

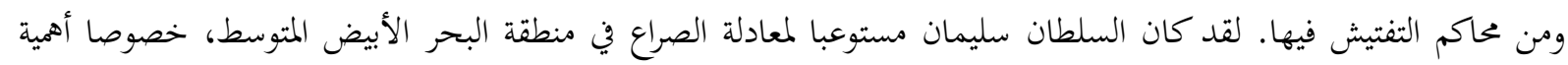

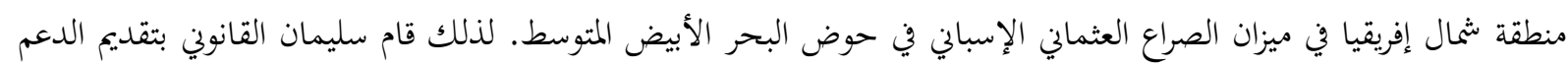

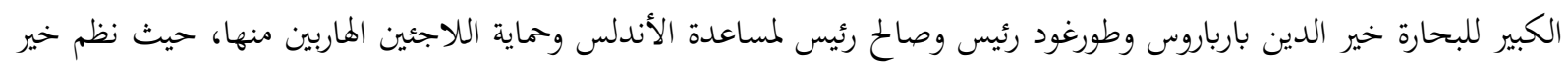

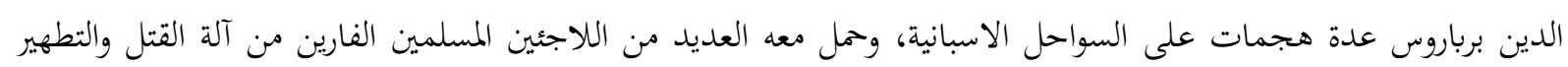
الديني الإسباني المسيحي (225-Özdemir, 1994, s. 224). وفي ظل هذه المتغيرات الجدية على مستوى الشرق الإسلامي، وبروز قوة العثمانيين، وكذلك في ظل اهيار الأندلس في يد

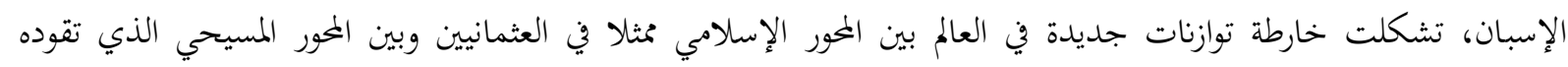

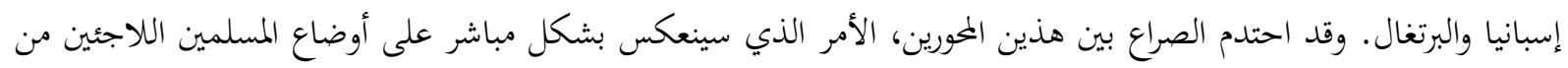

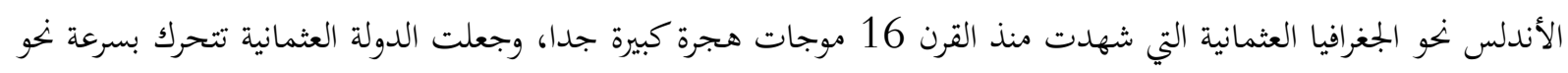

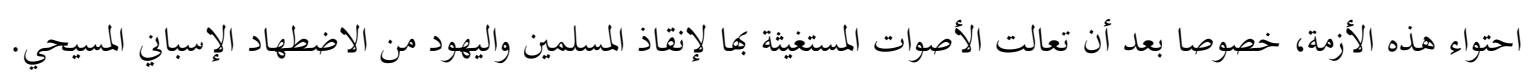
ورغم أن العثمانيين في البداية لم يستطيعوا أن يوجهوا جهودهم بشكل كلي نحو مساعدة مسلمي الأندلس، بسبب تعدد

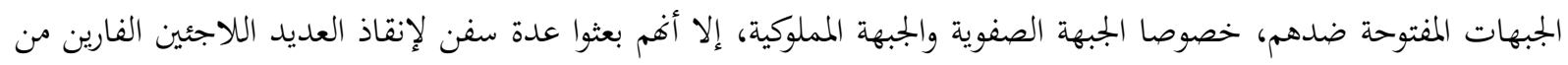
الأندلس. وأمام تصاعد حدة الصراع العثماني الإسباني في منطقة البحر الأبيض المتوسط وثمال إفريقيا زادت إسبانيا في ممارساهما

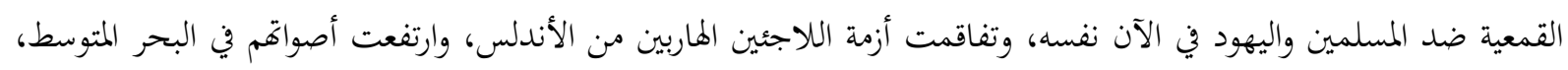

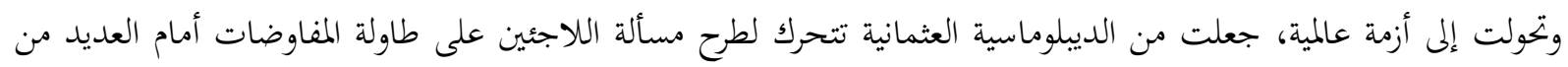

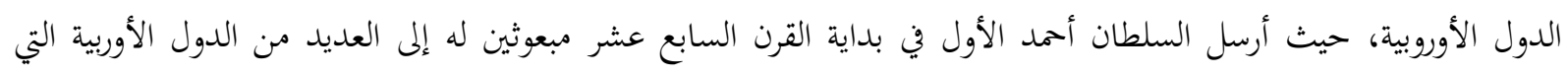
شهدت هي أيضا تدفقا للاجئين، وذلك بقصد التباحث وإيجاد حلول لاستقبال اللاجئين المسلمين واليهود الفارين من المحرقة

الإسبانية (229-Özdemir, 1994, s. 225).

\section{4- استراتيجية الدولة العثمانية تجاه أزمة اللاجئين:}

كان الهدف الأول للسياسة العثمانية في عهد السلطان سليمان القانوني هو السيطرة على منطقة البحر المتوسط ومنطقة شمال افريقيا، والوقوف ضد التمدد الإسباني الذي يحاول استطاع في القرن 15 السيطرة على مناطق استراتيجية فيها، وأصبح يمثل مديدا كبيرا للدولة العثمانية ووجودها في منطقة البحر المتوسط. لذلك حمل العثمانيون على عاتقهم أولوية تحرير الشمال الإفريقي، وقد نجحوا في ذلك في عهد سليمان القانوني، واكتمل في عهد السلطان سليم الثاني الذي أرسل فرمانا إلى علي قلج بلى باشا، ئأمره

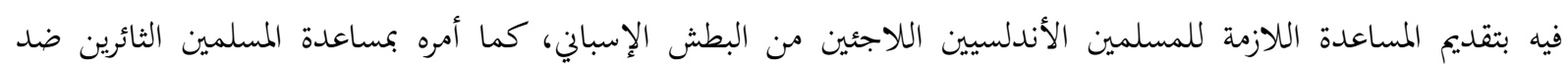
سلطات محاكم التفتيش الاسبانية (227-Özdemir, 1994, s. 223). لم تكن الاستراتيجية العثمانية تركز على إنقاذ المهاجرين الأندلسيين المسلمين فقط، بل كانت مهتمة أيضا بإنقاذ المهاجرين اليهود الذين كانوا يعيشون في الأندلس، وشملمتهم ممارسات الاضطهاد والقمع الصليبي الإسباني المتطرفة التي لا تعترف بأي دئي ديانة

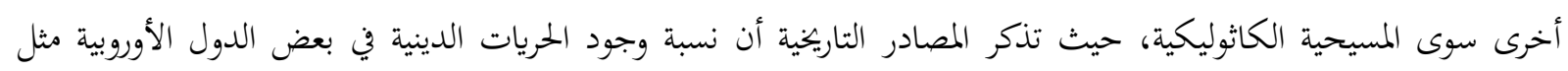

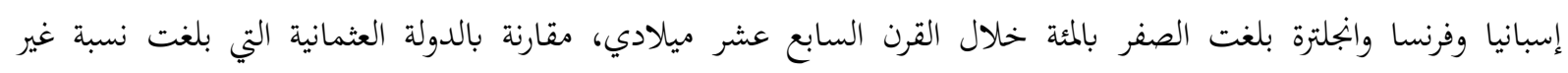

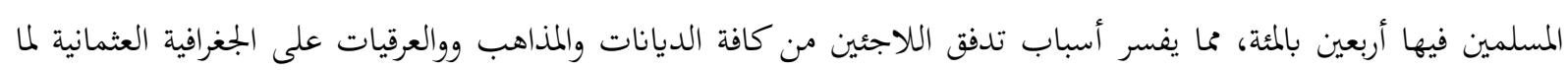


توفر فيها من مناخ واسع للحريات الدينية، بل إن نظام الملة الذي أصدره السلطان محمد الفاتح، وتم تطويره بشكل أوسع في عهد

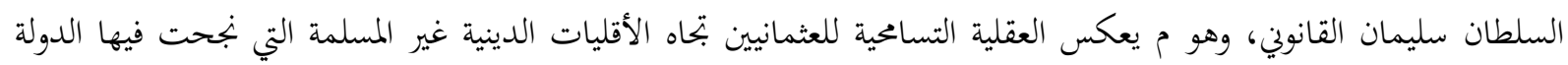

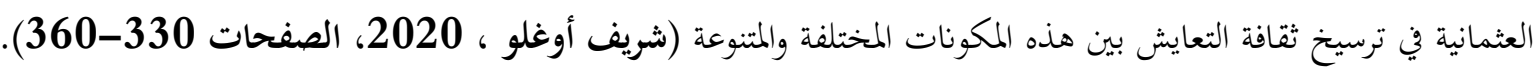
وقد ارتكزت الاستراتيجية العثمانية بتحاه مسألة المهاجرين الأندلسيين على ثلاثة مراحل أساسية، هي كالتالي:

أ- مرحلة إنقاذ المهاجرين:

كانت الدولة العثمانية تدرك حجم المخاطر التي يتعرض لها المسلمون واليهود على حد سواء في الأندلس، لذلك أرسلت

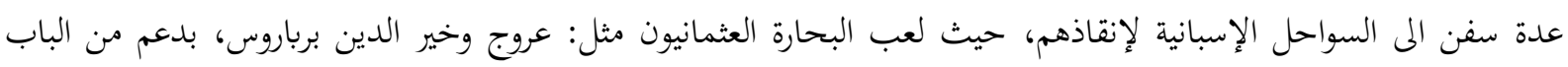

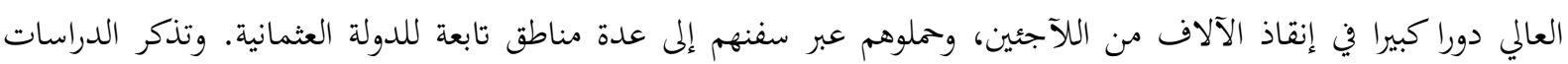

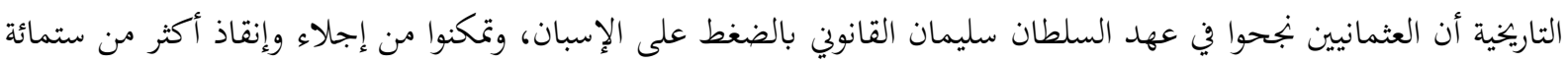
ألف لاجئ مسلم كانوا معرضين إلى الإبادة الجماعية من قبل الصليبين الإسبان، وكان السلطان العثماني قد هدد كل ألماني أوروبا بأنه إذا لم يتم توقيف قتل المسلمين في الأندلس فإنه سيقوم بقتل كل المسيحيين الموجودين في الشرق الإسلامي الخاضع للدولة العثمانية (الفيلالي، 2006، صفحة 247).

وفي الحقيقة يمكن القول إنه لولا هذا التهديد الجدي الذي وجهه السلطان سليمان القانوني إلى الإسبان وإلى كل الدول

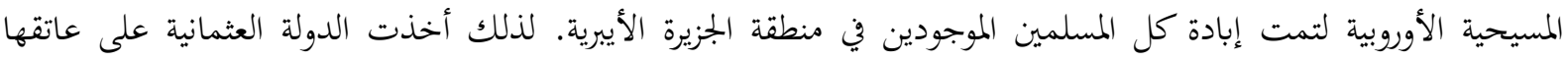

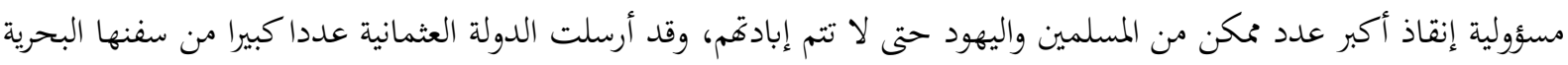

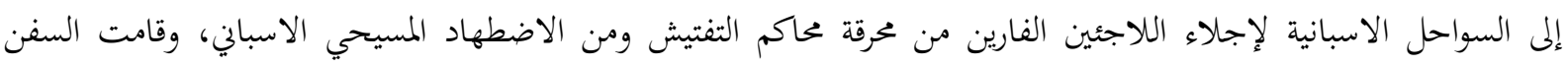

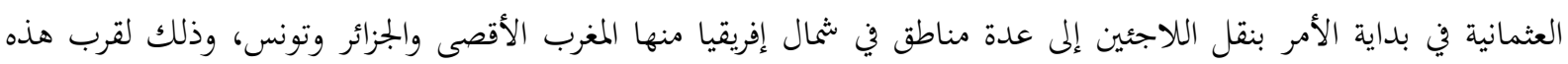

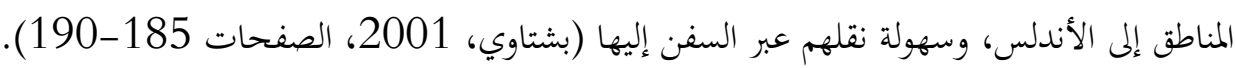

\section{ب- مرحلة توطين اللاجئين:}

أصبحت الدولة العثمانية بعد أن بسطت نفوذها على القسم الغربي من حوض البحر الأبيض المتوسط تمديدا جديا لأوربا

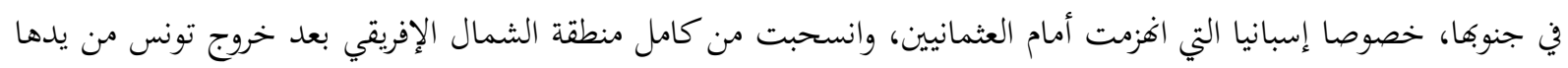

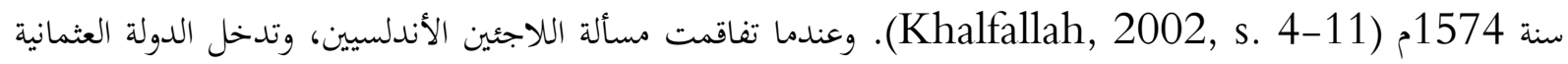
لإنقاذهم من الاضطهاد الإسباني، طرح السؤال الكبير على الدولة العثمانية وهو: ماهي الأماكن التي يمكن أن يتم فيها توطين

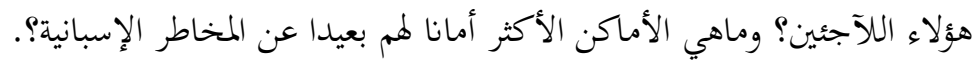

عملت الدولة العثمانية على وضع خطة محكمة لتوزيع هذه الأعداد الكبيرة للآجئين، وحددت الأماكن التي سيتم فيها هذا التوزيع، وكان من بين هذه الأماكن الجزائر وتونس وليبيا، وإزمير، والبلقان، والأناضول، وبعض المناطق الأوروبية. وقد تمكن

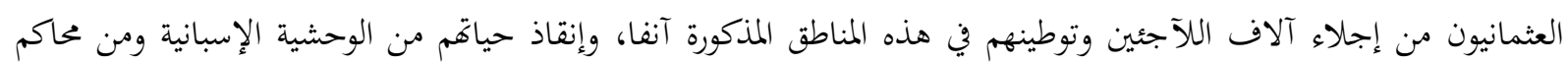

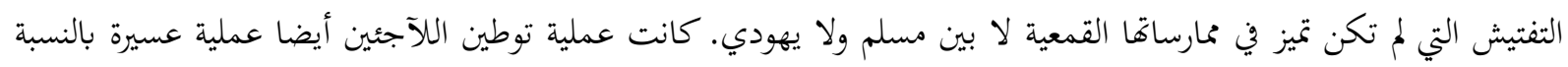

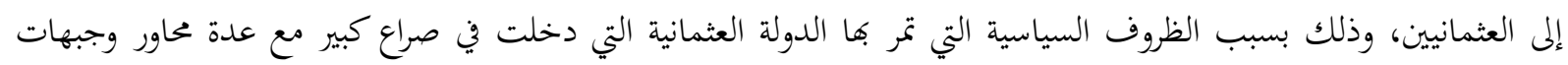

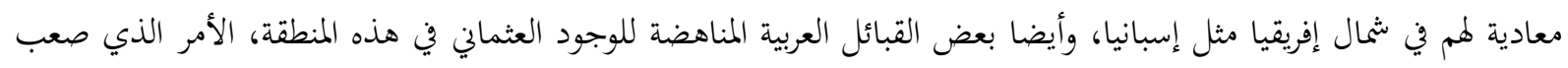

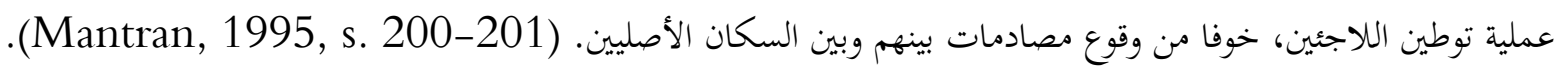
أما على مستوى جبهة المشرق العربي، فقد كان الصراع محتدم بين العثمانيين والبرتغاليين الذين نجحوا في الاستيلاء على

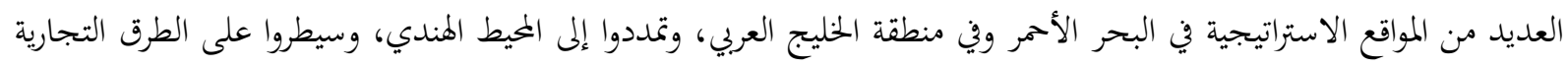


والممرات المائية الأهم مثل مضيق هرمز ومضيق باب المندب. أمام هذا الانشغال العثماني بهذه الجبهات العسكرية الصليبية التي

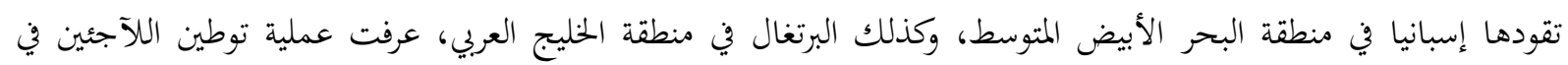

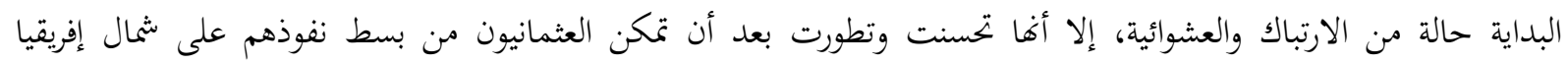

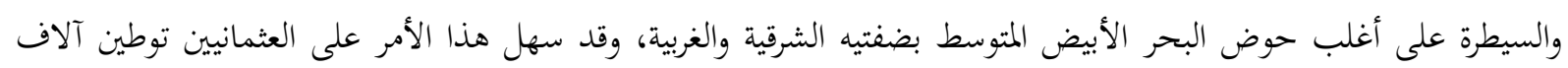

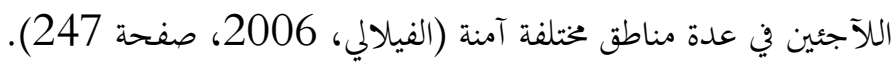

\section{- مواطن توطين المهاجرين الأندلسيين: - موإن}

تجحدر الإشارة هنا إلى أن عملية توطين اللآجئين تنقسم إلى ثلاثة أشكال، الأول يتمثل في عملية استيطان ذاتية قام بها

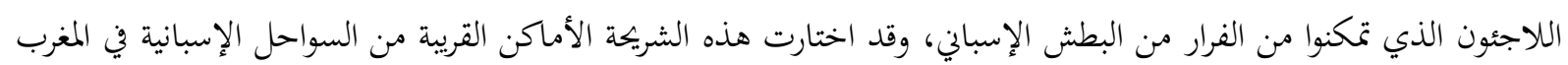

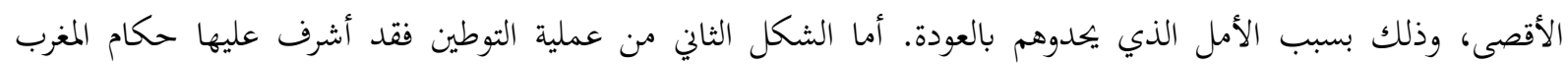

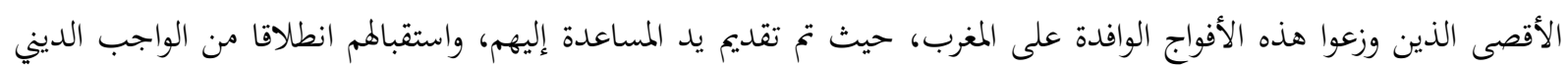

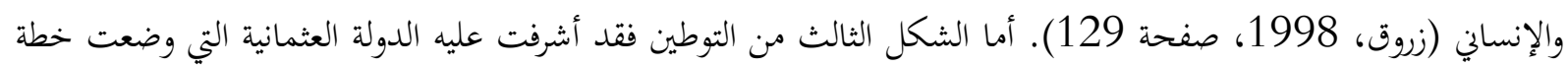

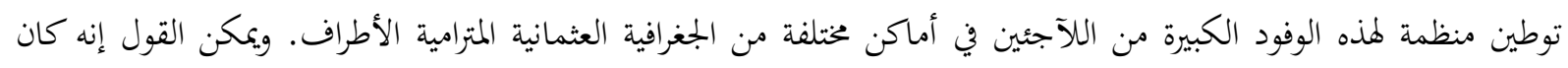

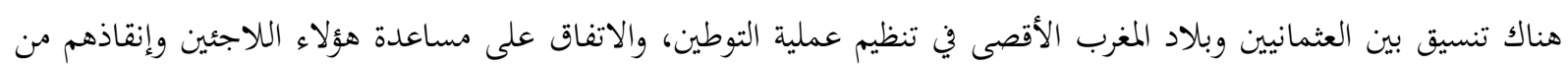

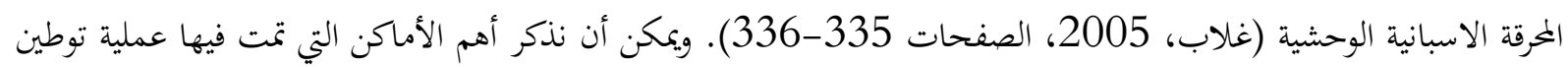
الاجئين الأندلسيين وهي كالتالي:

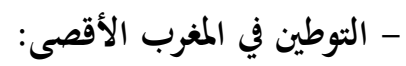

عرفت منطقة المغرب الأقصى تدفقا لعدد كبير من اللاجئين بعد سقوط غرناطة سنة 1492، وازدادت وتيرة موجات هذه

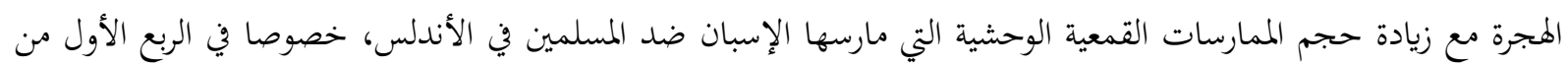

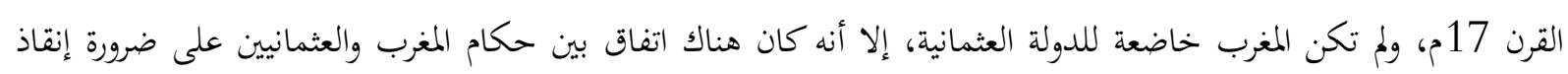

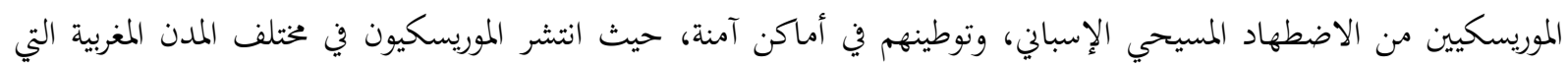

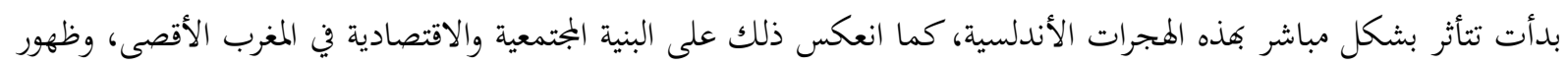

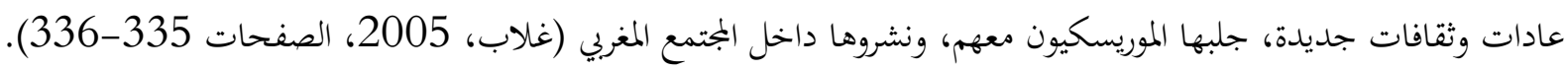

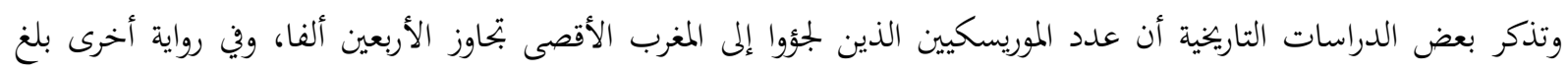

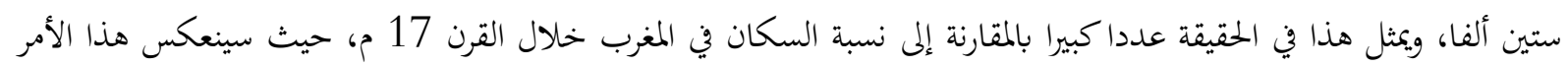

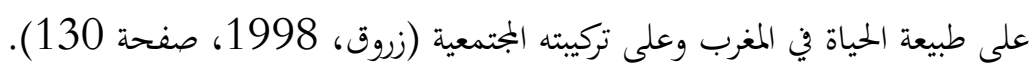

عندما حصلت محنة اللاجئين الأندلسيين وتفاقمت أكثر خلال القرن 16 م والقرن 17م، كانت الجزائر إيالة عثمانية، حيث تحرك العثمانيون منذ خير الدين برباروس بتوطين اللاجئين الأندلسيين في عدة مناطق جزائرية، وقدمت لهن لهم المساعدات

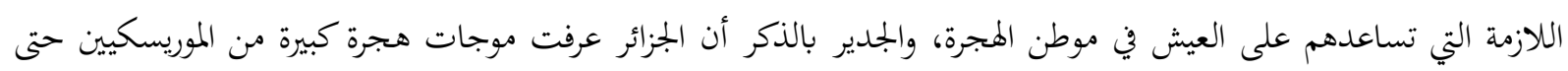

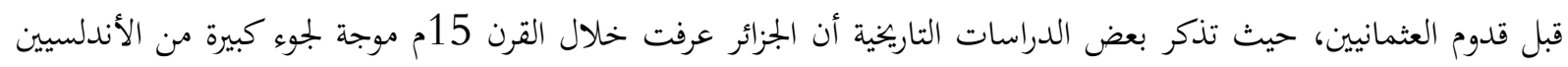

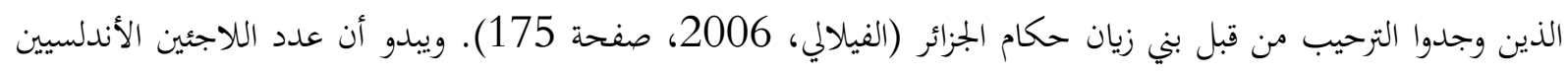

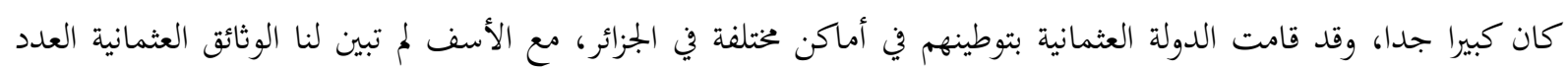

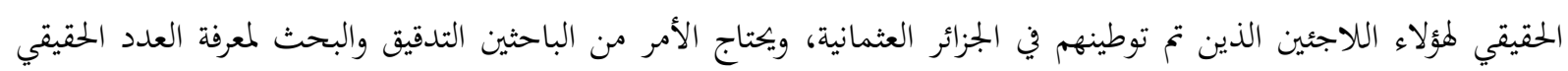


للاجئين الموريسكيين الذين وفدوا على الجزائر وعلى منطقة شمال إفريقيا مثلما يذكر ذلك المؤرخ المختص في الموريسكيين الدكتور

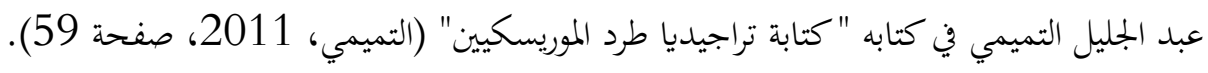
- التوطين في تونس: - n - n

منذ أن أصبحت إيالة عثمانية سنة 1574م تحولت تونس إلى قبلة للاجئين الأندلسيين الفارين من البطش الإسباني، وربما

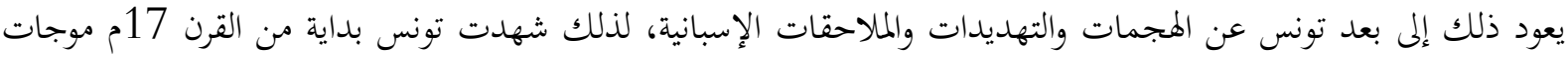

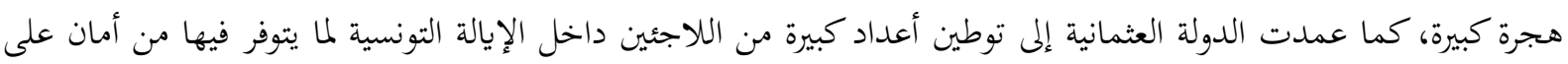

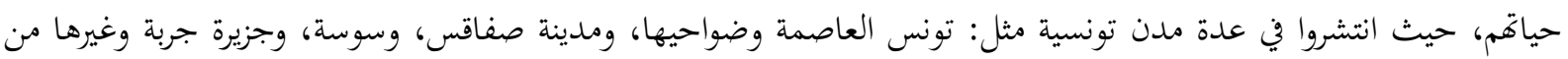

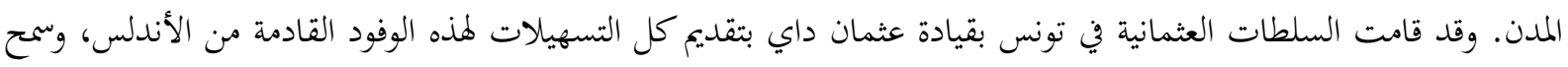
لهم ببناء البيوت والقرى والمدن مثل: تستور وقلعة الأندلس وغيرها، مما خلق هذا حركية كبيرة ودينامكية في الدورة الاقتصادية للإيالة التونسية (وآخرون، 1991، الصفحات 189-190). وبحدر الإشارة هنا إلى أن السياسة العثمانية في توطين اللاجئين الموريسكيين كانت تأخذ بعين الاعتبار مسألة أمن هؤلاء اللاجئين وتوطينهم في أماكن أكثر أمان، وبعيدة عن التهديدات الاسبانية التي تلاحقهم في كل مكان، وكانت تونس أحد أهم الإيالات التي وطن فيها العثمانيون أعدادا كبيرة من اللاجئين

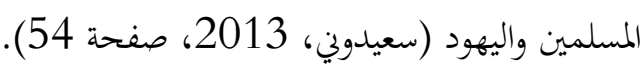

\section{- توطين في مختلف الجغرافيا العثمانية:}

قامت الدولة العثمانية أيضا بتوطين اللاجئين الأندلسيين من مسلمين ويهود في مناطق أخرى من الجغرافية العثمانية، مراعية في ذلك الحالة الدينية والمذهبية لمؤلاء اللاجئين، وقد تمت عملية توطين اليهود في سلانيك، وفي الشام وفي وإزمير واستانبول

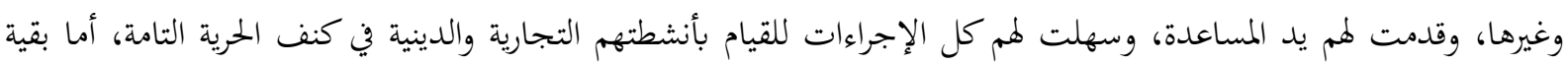
اللاجئين المسلمين فقد تم توطين قسم منهم في مناطق الاناضول والبلقان والشام وغيرها، ومنحتهم الأراضي للفلاحة، وسهلت لهم كل الاجراءات من أجل ممارسة أنشطتهم التجارية والعلمية والدينية بكل حرية (Lütfi, 2007, s. 30-38).

ج- مرحلة إدماج اللاجئين:

لم تكن عملية توزيع العثمانيين للاجئين الأندلسيين عشوائية، وإنما كانت عملية مدروسة تراعي الانتماء الديني والمذهبي وحتى المهني، وكذلك المستوى الاجتماعي. وكان الهدف من هذا هو خلق حالة من الاندماج داخل المناطق الجديدة التي سيتم

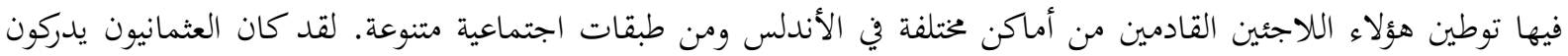
جيدا أهمية مسألة إدماج هؤلاء اللاجئين، لأفا عملية ستساهم بشكل كبير في خلق استقرار بجتمعي من ناحية، وكذلك بخلق حالة من الديناميكية والحيوية في تلك المناطق من ناحية أخرى (28) (Luitfi, 2007, s. 30). من جهة أخرى كان هناك عدد كبير من هؤلاء اللاجئين يتمتعون بمهارات، ويتقنون حرفا وعلوما سينقلوها إلى أماكن

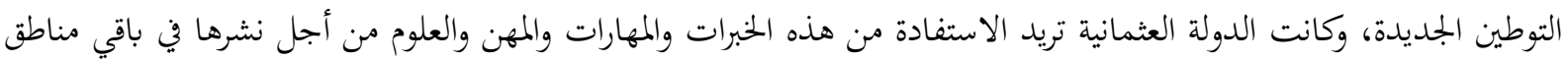

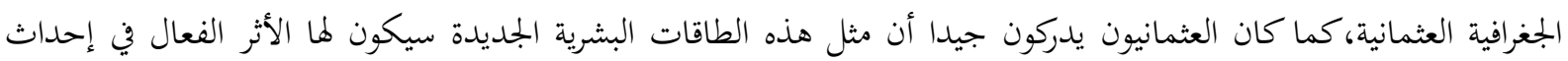

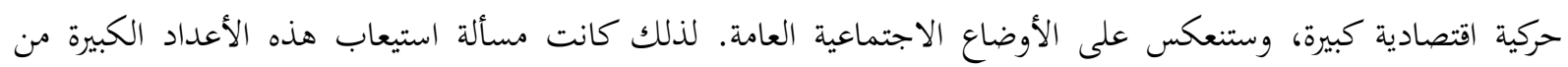

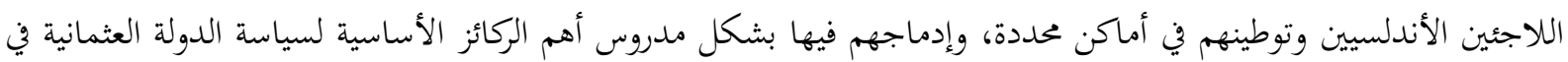

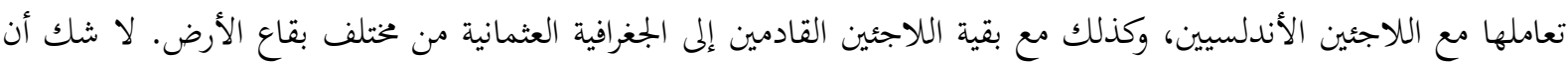

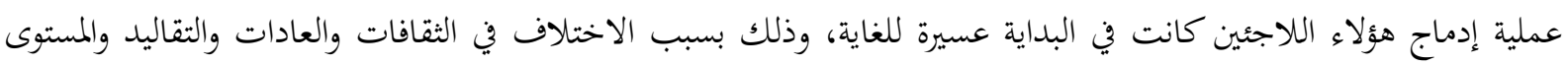


الاجتماعي العلمي والمهني، خصوصا أن أغلب اللاجئين القادمين يتكلمون اللغة الإسبانية، ولا يعرفون اللغة العربية أو التركية

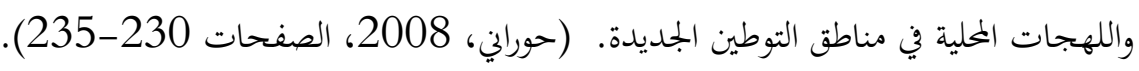

لقد عملت الدولة العثمانية على تذليل مثل هذه العقبات من خلال مساعدقم على التواصل مع المجتمعات الجديدة،

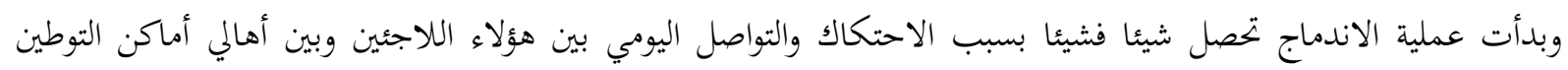

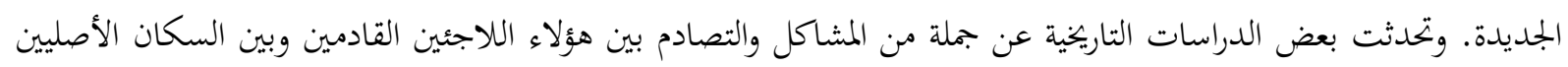

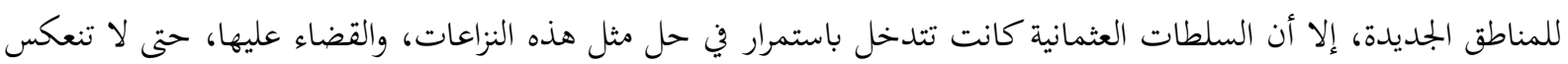

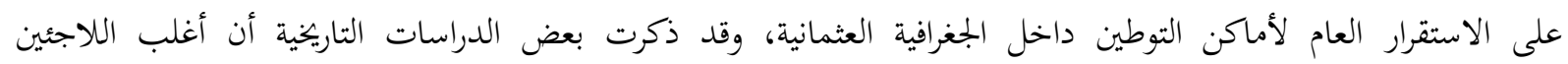

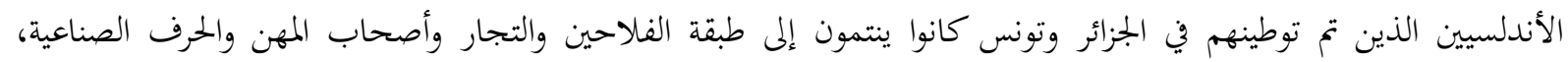
فانعكس ذلك على الأوضاع الاقتصادية في تلك المدن الشمال إفريقية، وتحركت فيها الدورة الاقتصادية مثل مدينة وهران بالجزائر

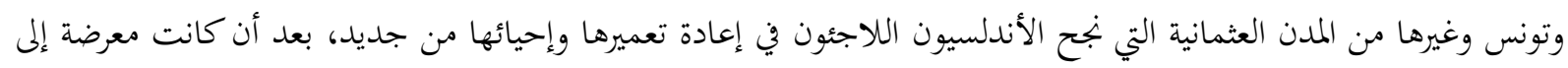
الخراب والاندثار، كما قاموا بزراعة الأرض وصناعة السفن وفتح مصانع للنسيج، خصوصا صناعة الحرير بسبب توفر التبات أشجار

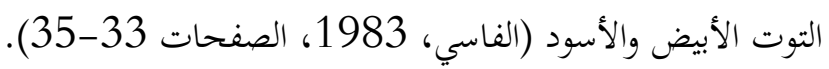

لقد امتزجت الثقافات والعادات والتقاليد التي أتى بها اللاجئون الأندلسيون مع الحالة الثقافية والمجتمعية داخل المناطق التي

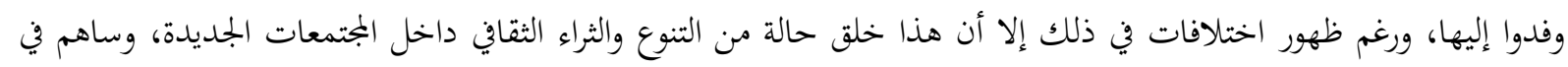

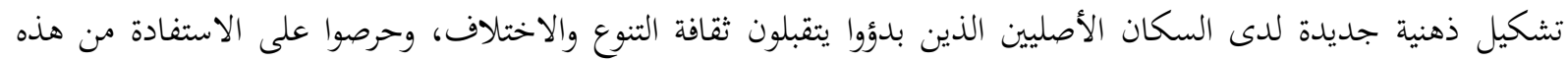

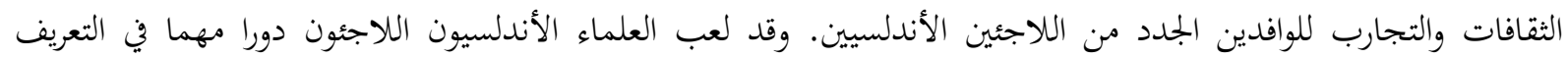
بالثقافات والعادات الأندلسية، مما سهل عملية الاندماج أكثر وبناء جسور تواصل مع الأهالي (Lütfi, 2007, s. 337-344). ويمكن القول إن اللاجئين الموريسكين نجحوا في عملية الاندماج، واستطاعوا أن يتحولوا إلى أحد المكونات الأساسية في

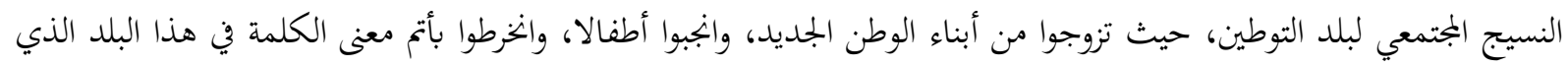

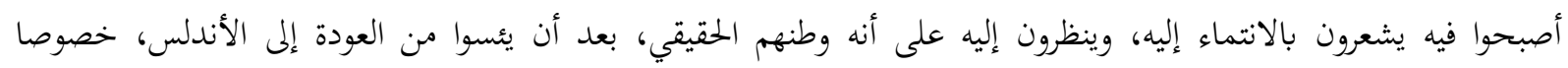

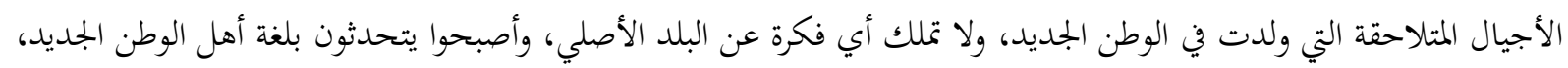

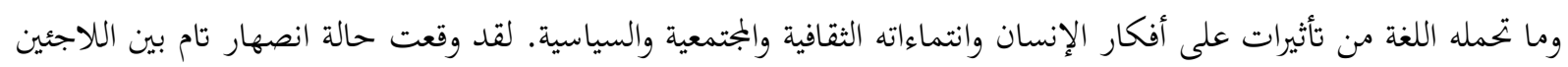

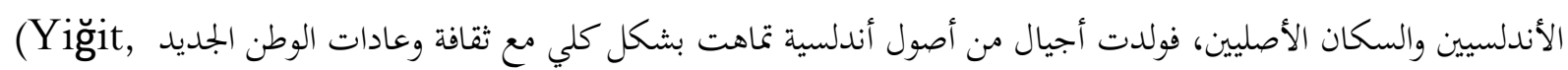

\section{5- 5 سياسة العثمانيين تجاه اليهود اللاجئين من الأندلس:}

تعاملت الدولة العثمانية منذ بداية محنة اللاجئين الأندلسيين الفارين من الوحشية الإسبانية من منطلق إنساني ومن منطلق

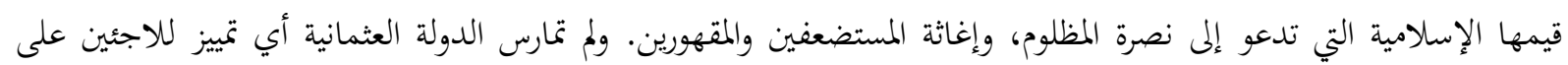

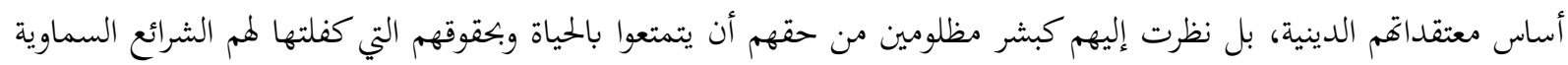

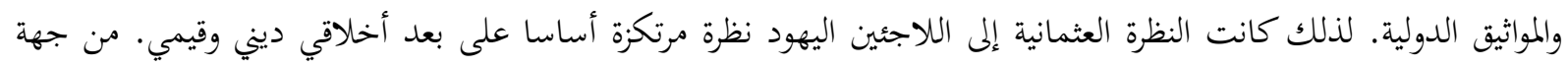

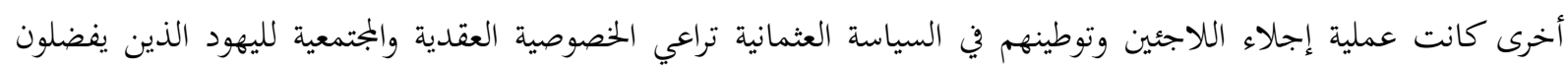
العيث مع بعضهم البعض في مجموعات متقاربة مع بعضهم وفي أماكن خاصة، تسمح لهم بممارسة معتقداتم الدينية وعاداتم

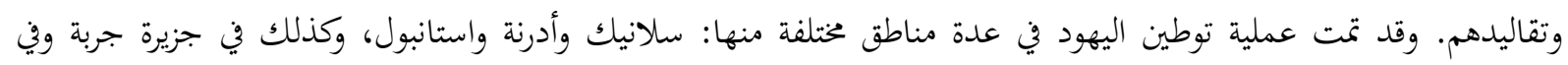


منطقة صفد وغيرها من المناطق التي يوجد فيها أقليات أخرى، ولم تجبر الدولة العثمانية اليهود على تغيير معتقداقم أو أسمائهم، بل

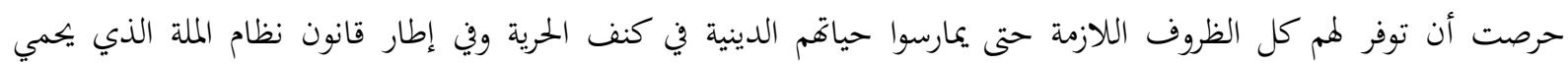
الطوائف الدينية غير المسلمة (Groepler, 1999, s. 134).

حرصت الدولة العثمانية أن تنقذ اللاجئين اليهود دون النظر إلى أوضاعهم الاجتماعية، فلم تفرق بين غني أو فقير، ولم

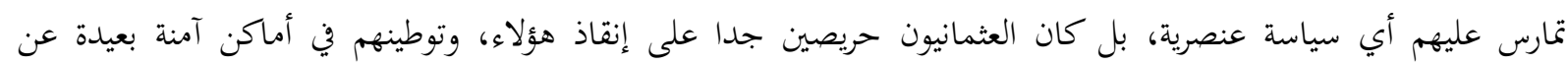
التهديدات الإسبانية، ووفرت لهم كل الظروف المناسبة لكي يتعايشوا كجماعات تتمتع بكل حقوقها، واشترطت عليهم الالتزام

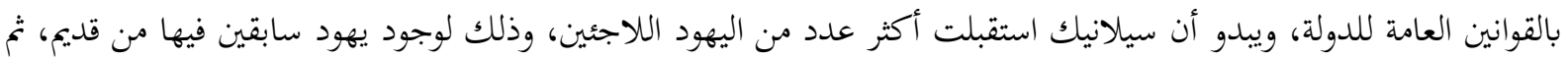
لكوها مدينة مناسبة جدا في خصوصيتها الاجتماعية لليهود (Lütfi, 2007, s. 352-355). وقد انتهجت الدولة العثمانية سياسة إدماج لليهود اللاجئين قائمة على أساس الخصوصية الدينية المناسبة لهم، وحاولت أن تقدم لهم يد المساعدة المادية

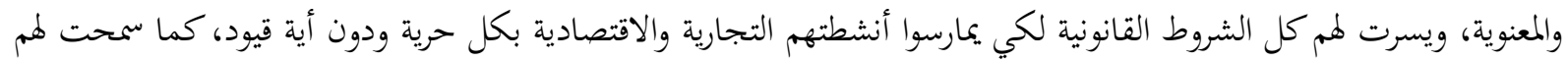

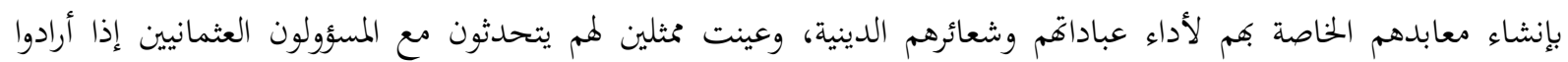

مساعدة من الدولة أو اللجوء لحل بعض المشاكل والصعوبات التي يعيشوها (41- Groepler, 1999, s. 38). لقد ساهمت هذه السياسة المتساعحة التي انتهتها الدولة العثمانية بحاه اللاجئين اليهود في انخراطهم في المجتمع العثماني، وأصبحوا فاعلين فيه ومستفيدين من القوانين التي سنتها الدولة العثمانية لحماية الطوائف الدينية غير المسلمة، كما استفاد اليهود

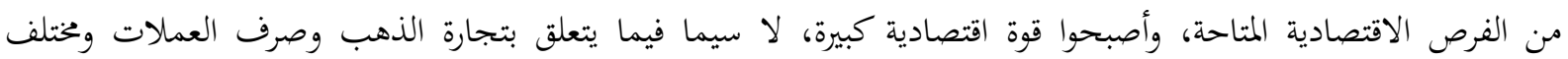
القطاعات التجارية المختلفة، خصوصا في استانبول وإزمير وعدة مدن عثمانية أخرى مثل: القاهرة والاسكندرية ودمشق وتونس تهره

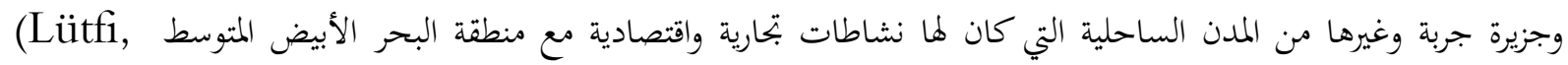
2007, s. 367-369)

إضافة إلى هذا كانت الدولة العثمانية ترغب في الاستفادة من اللاجئين اليهود ومدى قدرقم على خلق حيوية اقتصادية وبتارية، ستعود بالنفع على الدولة العثمانية وعلى المجتمع العثماني. غير أنه يجب الإشارة إلى أن اليهود سيتحولون فيما بعد إلى لئل

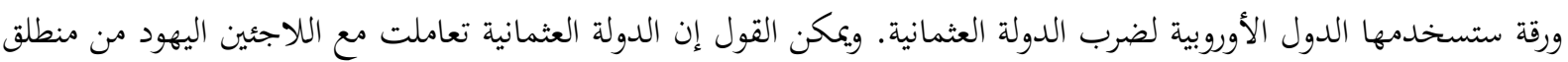
مرجعيتها الإسلامية التي تدافع عن المظلومين مهما كانت انتماءاقم العرقية أو الدينية والمذهبية، وكذلك من منطلق إنساني يحترم الإنسان ويدافع عن حقوقه وحريته الدينية والقانونية، كما كان رغبة العثمانيين في الآن نفسه هي الاستفادة اقتصاديا وبحاريا من هذه الطاقات البشرية التي كانت في الأندلس.

الخاتمة:

نخلص القول في بحثنا هذا إلى أن ظاهرة الهجرة واللجوء مثلت أحد أهم المشاكل التي عانت منها الشعوب والدول في نفس الوقت. ولعل الدولة العثمانية كانت أكثر الدول التي عرفت موجات هجرة كبيرة من عدة مناطق مختلفة، لأسباب مختلفة. وتعد موجات هجرة اللاجئين الأندلسيين الفارين من القمع الإسباني من القرن 15 إلى القرن 17 م أحد أهم الأزمات الإنسانية

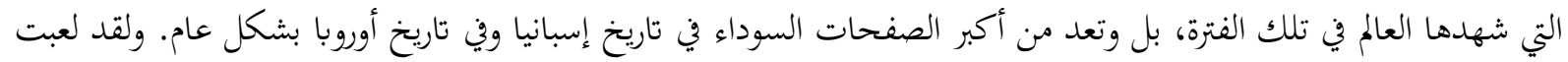

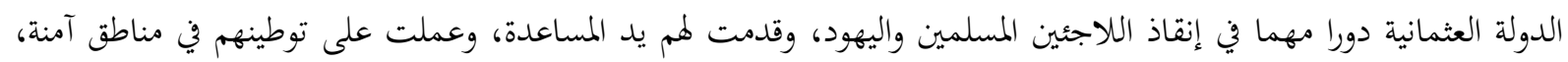

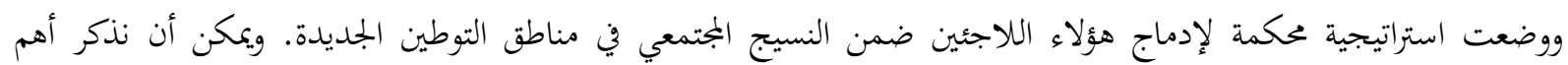
النتائج التي توصلنا إليها في بحثنا هذا وهي كالتالي: 
- أزمة اللاجئين الأندلسيين لم تكن أزمة عابرة نتيجة لظروف سياسية عابرة، وإنما كانت أزمة تعكس العقلية الاسبانية المتطرفة التي لا تؤمن بالتعايش ولا بحرية الآخرين، كما تكشف عن عمق الأزمة في كامل أوروبا التي بينت لنا فيها الإحصائيات عن تدهور كبير جدا لحالة الحريات الدينية في داخلها.

- لعبت الدولة العثمانية دورا بارزا في إنقاذ هؤلاء اللاجئين من محرقة الاضطهاد الديني الإسباني، وسخرت كل إمكانياتا من أجل نقلهم إلى أماكن أخرى، بعيدا عن التهديدات الاسبانية. - انتهجت الدولة العثمانية استراتيجية مدروسة، تقوم على ثلاثة مراحل: مرحلة إنقاذ اللاجئين الهاربين من الاضطهاد الإسباني،

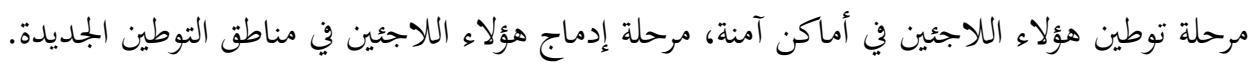
- لم تمارس الدولة العثمانية أثناء عملية إنقاذ اللاجئين الأندلسيين أي سياسة عنصرية أو دينية بين هؤلاء، بل استقبلت اليهود،

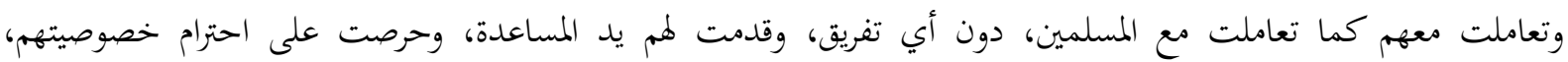
وتوطينهم في أماكن يستطيعون الاندماج فيها بسهولة. - مناخ الحريات الدينية والفكرية الذي كان سائدا في الدولة العثمانية جعلها ملاذا تلجأ إليها عدة عرقيات وأقليات من مختلف دول العالم، ومن مناطق أخرى تمر بأزمات مختلفة، كما تعاملت الدولة العثمانية مع ظاهرة الهجرات واللاجئين من منطلق مرجعيتها الإسلامية التي تؤمن بحرمة الإنسان، وتمنحه الأمان على حياته وعرضه ومتمتلكاته وحريته الدينية. - تشكف لنا أزمة اللاجئين الأندلسين حالة حقوق الإنسان والحريات الدينية في إسبانيا وأوروبا بشكل عام من القرن الخامس عشر الى حدود القرن السابع عشر ميلادي، كما تكشف لنا هذه الأزمة حالة الحريات الدينية وواقع الأقليات الدينية داخل الدولة

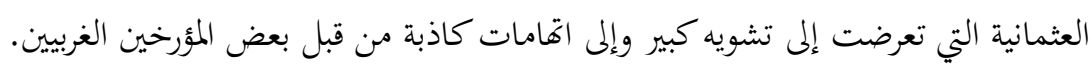
- سياسة التوطين التي انتهجتها الدولة العثمانية لهؤلاء اللاجئين كانت مدروسة، وتراعي الخصوصية الاجتماعية للاجئين، كما أن

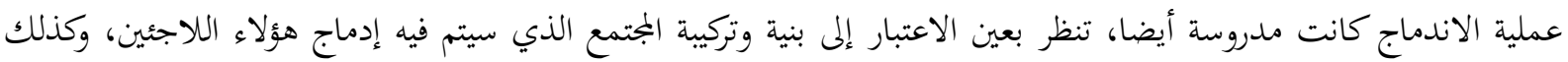
توفير الدولة العثمانية كل الشروط والظروف اللازمة لإنجاح عملية الاندماج بسهولة، وتحقيق استقرار حقيقي لهؤلاء اللاجئين. - دور اللاجئين الأندلسيين في التأثير على ثقافات وعادات مناطق التوطين الجديدة، ودورهم في خلق ديناميكية اقتصادية وعلمية واجتماعية داخل مجتمعات هذه المناطق، حيث نقلوا لمم علوما وبتحارب جديدة استفادوا منها كثيرا. 


$$
\begin{aligned}
& \text { ألبرت حوراني. (2008). تاريخ الشعوب العربية. دمشق: دار طلاس للدراسات والترجمة والنشر. }
\end{aligned}
$$

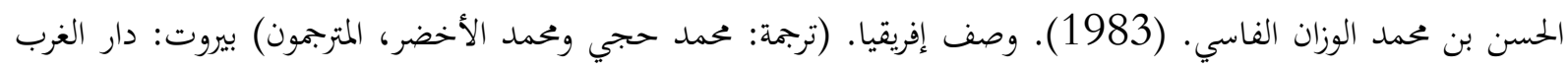

$$
\begin{aligned}
& \text { الإسلامي، طان. } \\
& \text { عادل سعيد بشتاوي. (2001). الأندلسيون المواركة. القاهرة: دار إهداءات. } \\
& \text { عبد الجليل التميمي. (2011). تراجيديا طرد الموريسكيين من الأندلس والمواقف الاسبانية والعربية منها (المجلد منشورات مركز }
\end{aligned}
$$

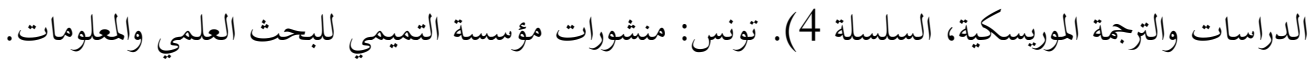

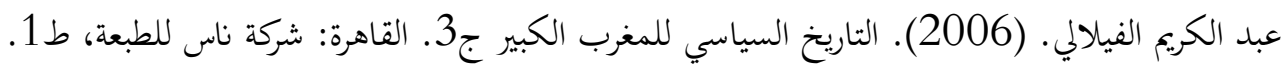

$$
\begin{aligned}
& \text { عبد الكريم غلاب. (2005). قراءة جديدة في تاريخ المغرب العربي عصر الإمبراطورية العهد التركي في تونس والجزائر. بيروت: } \\
& \text { دار الغرب الإسلامي طابد. } \\
& \text { متين شريف أوغلو. (2020). موقف الدولة العثمانية من مسألة التعايش وسياستها بتحاه الأقليات. تأليف التعايش وأشكاله من }
\end{aligned}
$$

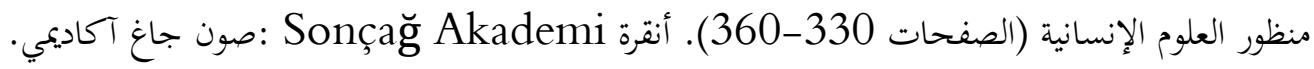

$$
\begin{aligned}
& \text { محمد المنوني وآخرون. (1991). التاريخ الأندلسي من خلال النصوص. الدار البيضاء: شركة النشر والتوزيع المدرسي، ط1 } 1 .
\end{aligned}
$$

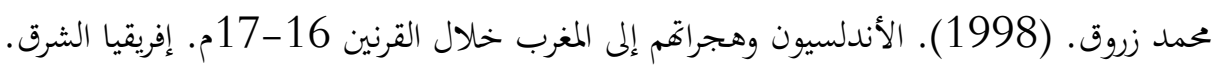

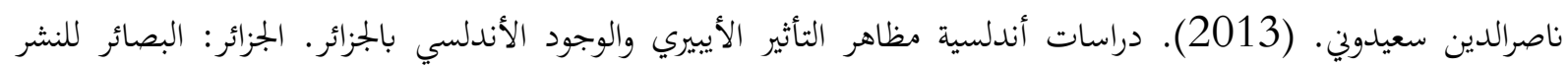

$$
\begin{aligned}
& \text { والتوزيع. }
\end{aligned}
$$

Aka, C. B. (1997). Modern Doğuşu İspanyol Altın Çă̆. Ankara: Dost Kitabevi.

Ataöv, T. (1987). Azınlıklar Üstüne Bazı Düşünceler. A.Ü. Siyasal Bilgiler Fakültesi Dergisi, c XLII(1-4).

Benjamin J.Kaplan, D. B. (2007). Religious Conflict and Practice of Toleration in Early Modern Europe. Cambridge: MA-Harvard Unniversity Press.

Bilgin, F. (2013). Endülüs'te Kalan Son Müslümanların (Moriskolar) İspanyadan Sürgünü(16091614). Din Bilimleri Akademik Araştırmaları Dergis(XIII(2).

C.E.BOSWORTH. (1982). The Concept Of Dhimma in Early İslam", Chiristians and Jews in

The Ottoman Empire". New York - London: Holmes \& Publişhers.

Groepler, E. (1999). İslam ve Osmanlı Dünyasında Yahudiler. (S. Kaya, Çev.) İstanbul: Belge Yayınları.

Güleryüz, N. A. (2015). Geçmişten Günümüze Anadolu’ya Yahudi Göçü. İstanbul: İstanbul Bilgi Üniversitesi Yayınları.

kapart, K. (1985). ottoman population 1830-1914. Madison university of Wisconsin.

Khalfallah, Z. (2002). Osmanlı İdaresinde Cerbe Adası XVI-XVII Yüzyıllar. İstanbul: Yüksek

Lisans Tezİ İstanbul Üniversitesii.

Lütfi, Ş. (2007). Mudejares \& Sefarades: Endülüs Müslüman ve Yahudilerin Osmanlıya Göçleri.

İstanbul: İz Yayıncilık.

Mantran, R. (1995). XVI-XVIII.Yüzyıllarda Osmanlı İmparatorluğu. Ankara: İmge Kitabevi.

Özdemir, M. (1994). Endülüs Müslümanları. Ankara: Türkiye Diyanet Vakfi Yayınlar. 
Paşa, Z. (2011). Ortaçağın Karanlık Çehresi: Engizisyon Mahkemeleri. İsanbul: İlk Taraf Yayınevi.

Sakaoğlu, N. (2002). Bu Mülkün Sultanları (36 Osmanlı Padişah). İstanbul: Oğlak Yayıncıllı.

Şener, A. (2010, Aralık ). Osmanlı Devletinde Dini Çeşitlilik: Farklı Neydi? Doğu Batı Dergisi(50).

Şerifoğlu, M. (2020). Osmanlı İmparatorluğunun Bir Arada Yaşama Konusundaki Tutumu ve Azınlıklara Yönelik Politikası. M. şerifoğlu içinde, Beşeri Bilimler Açısından Bir Arada Yaşama Kültürü ve Biçimleri (s. 329-360). Ankara: Son çağ Akademi.

Yiğit, İ. (2006). Murabitla. İstanbul: DİA Türkiye Diyanet Vakfi. 